Article

\title{
Postoperative Thromboembolism According to the Type of Surgery: A Nationwide Study in the Republic of Korea
}

\author{
Ka-Won Kang ${ }^{1}{ }^{(D}$, Ji Yoon Lee ${ }^{2,3}{ }^{1}$, Byung-Hyun Lee ${ }^{1}{ }^{D}$, Min Ji Jeon ${ }^{1}$, Eun Sang Yu ${ }^{1}$, Dae Sik Kim ${ }^{1}$, \\ Se Ryeon Lee ${ }^{1}$, Chul Won Choi ${ }^{1}$, Yong Park ${ }^{1}$ (D), Hwa Jung Sung ${ }^{1, *}$ and Byung Soo Kim ${ }^{1, *}$
}

1 Division of Hematology-Oncology, Department of Internal Medicine, Korea University College of Medicine, Seoul 02841, Korea; ggm1018@gmail.com (K.-W.K.); potato0430@hanmail.net (B.-H.L.); tinymj@naver.com (M.J.J.); imdryu@gmail.com (E.S.Y.); kay9801@naver.com (D.S.K.); logost@hanmail.net (S.R.L.); bonnie@korea.ac.kr (C.W.C.); paark76@hanmail.net (Y.P.)

2 Department of Biostatistics, Korea University College of Medicine, Seoul 02841, Korea; jinny1502@korea.ac.kr

3 Transdisciplinary Major in Learning Health Systems, Department of Healthcare Sciences, Graduate School, Korea University, Seoul 02841, Korea

* Correspondence: doctorsung@korea.ac.kr (H.J.S.); kbs0309@korea.ac.kr (B.S.K.); Tel.: +82-31-412-4938 (H.J.S.); +82-2-920-5690 (B.S.K.); Fax: +82-31-412-5802 (H.J.S.); +82-2-926-4534 (B.S.K.)

check for updates

Citation: Kang, K.-W.; Lee, J.Y.; Lee, B.-H.; Jeon, M.J.; Yu, E.S.; Kim, D.S.; Lee, S.R.; Choi, C.W.; Park, Y.; Sung, H.J.; et al. Postoperative

Thromboembolism According to the Type of Surgery: A Nationwide Study in the Republic of Korea. J. Clin. Med. 2022, 11, 1477. https://doi.org/ $10.3390 / j \mathrm{~cm} 11061477$

Academic Editor: Anders Gottsäter

Received: 5 February 2022

Accepted: 6 March 2022

Published: 8 March 2022

Publisher's Note: MDPI stays neutral with regard to jurisdictional claims in published maps and institutional affiliations.

Copyright: (C) 2022 by the authors. Licensee MDPI, Basel, Switzerland. This article is an open access article distributed under the terms and conditions of the Creative Commons Attribution (CC BY) license (https:// creativecommons.org/licenses/by/ $4.0 /)$.

\begin{abstract}
Postoperative thromboembolism (TE) is a serious, but preventable, complication in surgical patients. Orthopedic surgery, neurosurgery, and vascular surgery are considered high risk for TE, and current guidelines recommend TE prophylaxis. However, insufficient data exist regarding TE risk in other general surgeries. This study identified the actual incidence and relative risk of postoperative TE in the real world, according to surgery type. Twenty-six surgeries between 1 December 2017 and 31 August 2019 were selected from the Health Insurance Review and Assessment Service database and analyzed for postoperative TE events. Among all patients, $2.17 \%$ had a TE event within 6 months of surgery and $0.75 \%$ had a TE event owing to anticoagulant treatment. The incidence of total TE events was the highest in total knee replacement (12.77\%), hip replacement $(11.46 \%)$, and spine surgery $(5.98 \%)$. The incidence of TE with anticoagulant treatment was the highest in total knee replacement $(7.40 \%)$, hip replacement $(7.20 \%)$, and coronary artery bypass graft (CABG) surgery $(3.81 \%)$. Hip replacement, total knee replacement, CABG surgery, spine surgery, and cardiac surgery except CABG surgery, showed relatively higher risks for total claimed venous TE. The relative risk of venous TE with anticoagulant treatment was the highest for hysterectomy, partial hepatectomy, hip replacement, cardiac surgery except CABG surgery, and total knee replacement. The relative risk of arterial TE was the highest for cardiac surgery, total knee replacement, and hip replacement. In the real world, the incidence of postoperative TE events from total knee replacement and those from hip replacement remain high, and some surgeries could have a relatively higher risk of TE than other surgeries. For patients undergoing these surgeries, studies to reduce the incidence of postoperative TE in clinical practice should be conducted.
\end{abstract}

Keywords: thromboembolism; incidence; surgical procedures

\section{Introduction}

Postoperative thromboembolism (TE) is a serious, but preventable, complication in patients undergoing surgery. Three factors affect the development of TE: vascular injury, impairment of blood flow, and hypercoagulability [1]. To reduce the incidence of postoperative TE, surgical patients may be advised early walking, use of sequential compression devices, and antiplatelet or anticoagulant treatment. This is more apparent in patients who are particularly at risk for TE, namely those with cancer, atrial fibrillation, atrial flutter, or history of TE, as well as those scheduled to undergo surgeries that are known to be high risk for TE [2-5]. 
Surgery, in itself, increases the risk of TE, but some surgeries are categorized as having a high risk of postoperative TE [6,7]. Historically, these surgeries include orthopedic surgery, neurosurgery, and vascular surgery, and current guidelines recommend mechanical and pharmacological prophylaxis for TE in patients undergoing such procedures $[5,8,9]$. In the case of other general surgeries, patients are assessed for postoperative TE risk, either clinically or with the help of more objective measures such as the Caprini risk assessment model or the Rogers score [10,11]. The benefit of adding pharmacological prophylaxis to counteract the risk of bleeding is then left to the discretion of the physician [9,11-15]. Although objective measures exist, the risk for TE is mainly judged based on patient characteristics, and there are limited data on the extent of postoperative TE risk according to the type of surgery. In particular, there are limited data on TE risk in the Asian population, wherein TE risk is generally thought to be lower than that in Western countries.

Using a nationally representative database, this study aimed to identify the real-world incidence and pattern of postoperative TE in patients who had undergone commonly practiced surgeries and assess the relative risk for TE according to the type of surgery.

\section{Materials and Methods}

\subsection{Data Source}

In the Republic of Korea, the National Health Insurance (NHI), a universal health coverage system, covers approximately $98 \%$ of the population. NHI pays medical costs based on claims data, which consists of diagnosis, treatment, procedures, and drug prescriptions [16,17]. The claims data are anonymized and made available for healthcare service research in the Health Insurance Review and Assessment Service (HIRA) database, which was used for this study. All procedures involving human participants in this study were performed in accordance with the ethical standards of the institutional and national research committees and in accordance with the 1964 Helsinki Declaration and its later amendments or comparable ethical standards. The study was approved by the institutional review board of the Korea University Anam Hospital (No. 2020AN0136). The requirement for informed consent was waived by the institutional review board of the Korea University Anam Hospital, owing to the use of anonymized patient data.

\subsection{Patients}

The 2019 Statistical Information Report for Major Surgical Statistics provided by the National Statistical Office was used to select surgeries commonly performed in the Republic of Korea (http:/ / kostat.go.kr/, accessed on 1 April 2020). The report consisted of data on 33 surgeries, including 16 surgeries of international interest and 17 surgeries reflecting domestic conditions. Among them, 26 surgeries that either required general anesthesia or were considered commonly performed procedures were selected for the present study.

We extracted all data from the HIRA database of each patient who had undergone the selected surgeries between 1 December 2017 and 31 August 2019 and analyzed TE events of these patients from the date of surgery up to 6 months (Table S1).

\subsection{Clinical Endpoints}

The primary endpoints were the incidence of postoperative TE and its relative risk according to the type of surgery. 'Postoperative TE events' was defined as (1) patients with any venous and arterial TE events that were claimed within 6 months from the date of the surgery (total claimed TE); and (2) patients with venous and arterial TE events that were claimed within 6 months from the date of the surgery and treated with anticoagulant medications within 3 days of the date of TE diagnosis (TE with anticoagulant treatment).

'The patients who underwent prophylactic anticoagulant treatment' were defined as patients satisfying the following conditions, to distinguish them from those using the anticoagulant treatment for therapeutic purposes: (1) patients who were administered anticoagulant medications within 3 days of the date of the surgery, among those who had 
no TE events; or (2) patients who were administered anticoagulant medications from the day of surgery to 1 day before the diagnosis of TE events among those who had TE events.

The risk factors for TE included age, sex, history of cancer, atrial fibrillation or atrial flutter, history of TE, history of taking antiplatelet or anticoagulant drugs between 2 weeks and 3 months before surgery, antiplatelet or anticoagulant use on the day of surgery, and use of prophylactic anticoagulant treatment. The claims data for cancer, atrial fibrillation or atrial flutter, and TE diagnosis were limited to within 3 months from the date of surgery. Antiplatelet drugs included aspirin, clopidogrel, cilostazol, and ticagrelor, and anticoagulant drugs included apixaban, edoxaban, dabigatran, argatroban, enoxaparin, dalteparin, heparin, and warfarin.

\subsection{Statistical Analysis}

Continuous data are presented as means and standard deviations, and categorical data are presented as frequencies and percentages. The incidence of TE according to each surgery was calculated as the number of patients who met the definition for TE mentioned above. The adjusted odds ratios (ORs) for TE events were obtained using a multiple logistic regression model, with the following independent variables: age, sex, history of cancer, atrial fibrillation or atrial flutter, TE, antiplatelet or anticoagulant drug use between 2 weeks and 3 months before surgery and on the day of surgery, and use of prophylactic anticoagulant treatment. The multivariable analysis results are presented as adjusted ORs and their 95\% confidence intervals (CIs). Transurethral prostatectomy was used as a reference category for the types of surgery. All statistical analyses were performed using SAS version 9.4 software (SAS Institute Inc., Cary, NC, USA).

\section{Results}

\subsection{Incidence of TE within 6 Months from the Date of Surgery}

Data of a total of 2,799,293 patients who underwent the selected surgeries between 1 December 2017 and 31 August 2019 were analyzed. Among those patients, 60,683 (2.17\%) had a TE event within 6 months from the date of surgery and 21,063 (0.75\%) had a TE event following anticoagulant treatment (Table 1). With respect to TE in the anticoagulant treatment group, the median duration of anticoagulant therapy was 13 days (range: 1-442 days).

Table 1. Incidence of thromboembolism within 6 months from the date of each surgery.

\begin{tabular}{|c|c|c|c|c|}
\hline \multirow[b]{2}{*}{ Surgery } & \multirow[b]{2}{*}{ Total Patients, $n$} & \multicolumn{3}{|c|}{ Thromboembolism within 6 Months from the Date of Surgery } \\
\hline & & $\begin{array}{c}\text { A: Total Claimed } \\
\text { Thromboembolism, } n \\
(\%)\end{array}$ & $\begin{array}{l}\text { B: Thromboembolism } \\
\text { with Anticoagulant } \\
\text { Treatment, } n(\%)\end{array}$ & $\mathrm{B} / \mathrm{A}(\%) *$ \\
\hline Total knee replacement & 108,111 & $13,811(12.77)$ & $7995(7.40)$ & 57.89 \\
\hline Hip replacement & 43,415 & $4975(11.46)$ & $3124(7.20)$ & 62.79 \\
\hline Spine surgery & 265,317 & $15,857(5.98)$ & $3336(1.26)$ & 21.04 \\
\hline Coronary artery bypass graft & 6591 & $343(5.20)$ & $251(3.81)$ & 73.18 \\
\hline Partial hepatectomy & 9322 & $429(4.60)$ & $331(3.55)$ & 77.16 \\
\hline $\begin{array}{l}\text { Cardiac surgery (except coronary } \\
\text { artery bypass graft) }\end{array}$ & 10,296 & $443(4.30)$ & $386(3.75)$ & 87.13 \\
\hline Gastrectomy & 27,203 & $1114(4.10)$ & $302(1.11)$ & 27.11 \\
\hline Hysterectomy & 20,831 & $714(3.43)$ & $540(2.59)$ & 75.63 \\
\hline Endoscopic spine surgery & 12,157 & $392(3.22)$ & $23(0.19)$ & 5.87 \\
\hline Brain tumor surgery & 11,516 & $302(2.62)$ & $173(1.50)$ & 57.28 \\
\hline Open prostatectomy & 3387 & $81(2.39)$ & $23(0.68)$ & 28.40 \\
\hline Cholecystectomy & 129,081 & $2511(1.95)$ & $828(0.64)$ & 32.97 \\
\hline
\end{tabular}


Table 1. Cont.

\begin{tabular}{|c|c|c|c|c|}
\hline \multirow[b]{2}{*}{ Surgery } & \multirow[b]{2}{*}{ Total Patients, $n$} & \multicolumn{3}{|c|}{ Thromboembolism within 6 Months from the Date of Surgery } \\
\hline & & $\begin{array}{c}\text { A: Total Claimed } \\
\text { Thromboembolism, } n \\
(\%)\end{array}$ & $\begin{array}{l}\text { B: Thromboembolism } \\
\text { with Anticoagulant } \\
\text { Treatment, } n(\%)\end{array}$ & $\mathrm{B} / \mathrm{A}(\%) *$ \\
\hline Transurethral prostatectomy & 18,547 & $342(1.84)$ & $85(0.46)$ & 24.85 \\
\hline Skull base surgery & 674 & $10(1.48)$ & $4(0.59)$ & 40.00 \\
\hline Cataract surgery & 907,397 & $12,819(1.41)$ & $2489(0.27)$ & 19.42 \\
\hline Total mastectomy & 22,091 & $280(1.27)$ & $98(0.44)$ & 35.00 \\
\hline Repair of inguinal hernia & 56,698 & $671(1.18)$ & $153(0.27)$ & 22.80 \\
\hline Partial excision of mammary gland & 63,033 & $586(0.93)$ & $130(0.21)$ & 22.18 \\
\hline Appendectomy & 137,344 & $1024(0.75)$ & $263(0.19)$ & 25.68 \\
\hline Thyroidectomy & 51,506 & $351(0.68)$ & $80(0.16)$ & 22.79 \\
\hline Sinus surgery & 158,677 & $867(0.55)$ & $82(0.05)$ & 9.46 \\
\hline Endoscopic sinus surgery & 109,454 & $578(0.53)$ & $115(0.11)$ & 19.90 \\
\hline Operation for hemorrhoid & 303,456 & $1401(0.46)$ & $158(0.05)$ & 11.28 \\
\hline Cesarean section & 255,600 & $684(0.27)$ & $84(0.03)$ & 12.28 \\
\hline Cleft lip and/or palate surgery & 1282 & $2(0.16)$ & $1(0.08)$ & 50.00 \\
\hline Tonsillectomy & 66,307 & $96(0.14)$ & $9(0.01)$ & 9.38 \\
\hline Total & $2,799,293$ & $60,683(2.17)$ & $21,063(0.75)$ & 34.71 \\
\hline
\end{tabular}

Note: ${ }^{*} \mathrm{~B} / \mathrm{A}$ represents the ratio of thromboembolism events with anticoagulant treatment from the total claimed thromboembolism events.

The incidence of total claimed TE events was the highest for total knee replacement $(13,811 / 108,111$ patients, $12.77 \%)$, hip replacement (4975/43,415 patients, $11.46 \%)$, and spine surgery $(15,857 / 265,317$ patients, $5.98 \%)$. In the case of TE in the anticoagulant treatment, the incidence was the highest in total knee replacement $(7995 / 108,111$ patients, $7.40 \%)$, hip replacement (3124/43,415 patients, $7.20 \%)$, and coronary artery bypass graft surgery (251/6591 patients, $3.81 \%)$. Approximately $65 \%$ of TE events occurred within 1 month of surgery (Figure 1).

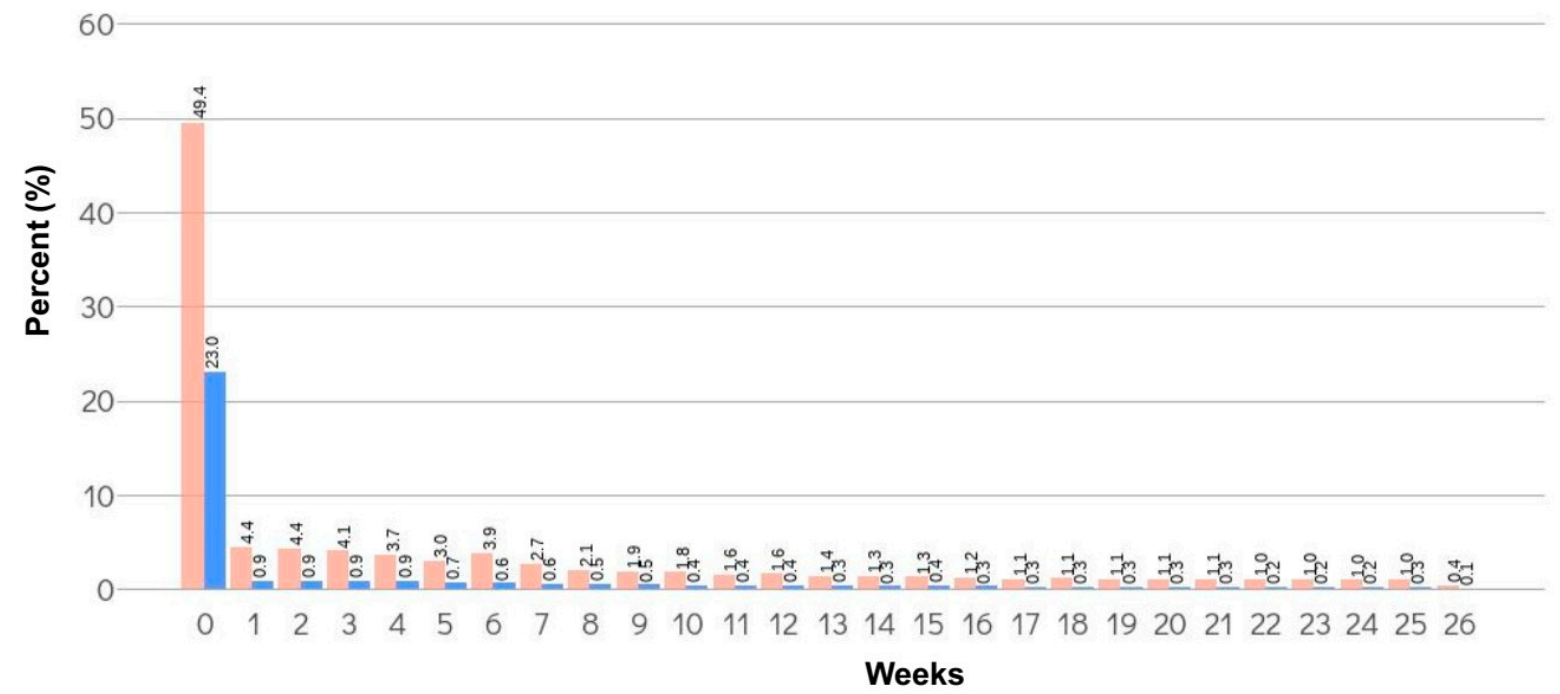

Figure 1. Distribution of TE events within 6 months from the date of surgery. The distribution of TE events within 6 months from the date of surgery is shown as the percentage from a total of 60,683 patients with TE (pink bar: total claimed TE, blue bar: TE with anticoagulant treatment).

3.2. Proportion of Patients Who Underwent Prophylactic Anticoagulant Treatment and Its Effect on the Incidence of TE Events

Among 2,799,293 patients enrolled in this study, 158,987 patients underwent prophylactic anticoagulant treatment (mean: $5.68 \%$, range: $0.06-96.77 \%$ according to the type of surgery). The proportions of patients who underwent prophylactic anticoagulant treatment 
for each type of surgery were $52.62 \%$ in total knee replacement, $41.17 \%$ in hip replacement, $9.06 \%$ in spine surgery, $40.77 \%$ in partial hepatectomy, $26.18 \%$ in gastrectomy, and $18.96 \%$ in hysterectomy. The incidence of postoperative TE events from prophylactic anticoagulant treatment was approximately $90 \%$ lower than that with no treatment (Table 2).

\subsection{Type of TE within 6 Months from the Date of Surgery}

The types of total claimed TE and TE with anticoagulant treatment are summarized in Table 3. In the total claimed TE, $79.78 \%(48,412 / 60,683$ patients) of patients were diagnosed with venous TE and $20.22 \%(12,271 / 60,683$ patients) with arterial TE. In the cases where the location was identified, the lower extremities were the most common location for venous TE $(18,690 / 48,410$ patients, $38.61 \%)$. For arterial TE, the extremities in general were the most common location $(1780 / 12,273$ patients, $14.50 \%)$. In TE with anticoagulant treatment, $91.27 \%(19,224 / 60,683$ patients) of patients were diagnosed with venous TE and $8.73 \%$ $(1839 / 60,683$ patients) with arterial TE. Myocardial infarction occurred in $0.023 \%$ of patients $(14 / 60,683$ patients), stroke in $0.089 \%$ (54/60,683 patients), and pulmonary embolism in $0.003 \%(2 / 60,683$ patients). The types of total claimed TE and TE with anticoagulant treatment according to each surgery type are presented in Tables S2 and S3. 
Table 2. Proportion of patients who underwent prophylactic anticoagulant treatment and its effect on the incidence of TE events.

\begin{tabular}{|c|c|c|c|c|c|c|c|c|}
\hline \multirow[b]{2}{*}{ Surgery } & \multirow[b]{2}{*}{$\begin{array}{c}\text { Total } \\
\text { Patients, } n\end{array}$} & \multirow{2}{*}{$\begin{array}{c}\text { Patients Who } \\
\text { Underwent } \\
\text { Prophylactic } \\
\text { Anticoagulant } \\
\text { Treatment, } n(\%)\end{array}$} & \multicolumn{3}{|c|}{ Total Claimed Thromboembolism, $n(\%)$} & \multicolumn{3}{|c|}{ Thromboembolism with Anticoagulant Treatment, $n(\%)$} \\
\hline & & & $\begin{array}{l}\text { With Prophylactic } \\
\text { Anticoagulant } \\
\text { Treatment }\end{array}$ & $\begin{array}{c}\text { Without } \\
\text { Prophylactic } \\
\text { Anticoagulant } \\
\text { Treatment }\end{array}$ & $p$ Value & $\begin{array}{l}\text { With Prophylactic } \\
\text { Anticoagulant } \\
\text { Treatment }\end{array}$ & $\begin{array}{c}\text { Without } \\
\text { Prophylactic } \\
\text { Anticoagulant } \\
\text { Treatment }\end{array}$ & $p$ Value \\
\hline Total knee replacement & 108,111 & $56,887(52.62)$ & $1717(1.59)$ & $12,094(11.19)$ & $<0.001$ & $551(0.51)$ & $7444(6.89)$ & $<0.001$ \\
\hline Hip replacement & 43,415 & $17,876(41.17)$ & $684(1.58)$ & $4291(9.88)$ & $<0.001$ & $350(0.81)$ & $2774(6.39)$ & $<0.001$ \\
\hline Spine surgery & 265,317 & $24,029(9.06)$ & $1131(0.43)$ & $14,726(5.55)$ & $<0.001$ & $551(0.21)$ & $2785(1.05)$ & $<0.001$ \\
\hline Coronary artery bypass graft & 6591 & $6378(96.77)$ & $162(2.46)$ & $181(2.75)$ & 0.305 & $70(1.06)$ & $181(2.75)$ & $<0.001$ \\
\hline Partial hepatectomy & 9322 & $3801(40.77)$ & $134(1.44)$ & $295(3.16)$ & $<0.001$ & $94(1.01)$ & $237(2.54)$ & $<0.001$ \\
\hline $\begin{array}{l}\text { Cardiac surgery (except } \\
\text { coronary artery bypass graft) }\end{array}$ & 10,296 & 9799 (95.17) & $216(2.10)$ & $227(2.20)$ & 0.601 & $161(1.56)$ & $225(2.19)$ & 0.001 \\
\hline Gastrectomy & 27,203 & $7123(26.18)$ & $164(0.60)$ & $950(3.49)$ & $<0.001$ & $79(0.29)$ & $223(0.82)$ & $<0.001$ \\
\hline Hysterectomy & 20,831 & 3949 (18.96) & $178(0.85)$ & $536(2.57)$ & $<0.001$ & $126(0.60)$ & 414 (1.99) & $<0.001$ \\
\hline Endoscopic spine surgery & 12,157 & $86(0.71)$ & $3(0.02)$ & $389(3.20)$ & $<0.001$ & $1(0.01)$ & $22(0.18)$ & $<0.001$ \\
\hline Brain tumor surgery & 11,516 & $4888(42.45)$ & $126(1.09)$ & $176(1.53)$ & 0.004 & $75(0.65)$ & $98(0.85)$ & 0.0804 \\
\hline Open prostatectomy & 3387 & $1708(50.43)$ & $44(1.30)$ & $37(1.09)$ & 0.437 & $9(0.27)$ & $14(0.41)$ & 0.2971 \\
\hline Cholecystectomy & 129,081 & $10,164(7.87)$ & $356(0.28)$ & $2155(1.67)$ & $<0.001$ & $202(0.16)$ & $626(0.48)$ & $<0.001$ \\
\hline Transurethral prostatectomy & 18,547 & $678(3.66)$ & $41(0.22)$ & $301(1.62)$ & $<0.001$ & $24(0.13)$ & $61(0.33)$ & $<0.001$ \\
\hline Cataract surgery & 907,397 & $2432(0.27)$ & $760(0.08)$ & $12,059(1.33)$ & $<0.001$ & $460(0.05)$ & $2029(0.22)$ & $<0.001$ \\
\hline Total mastectomy & 22,091 & $2278(10.31)$ & $66(0.30)$ & $214(0.97)$ & $<0.001$ & $33(0.15)$ & $65(0.29)$ & 0.001 \\
\hline Repair of inguinal hernia & 56,698 & $559(0.99)$ & $54(0.10)$ & $617(1.09)$ & $<0.001$ & $25(0.04)$ & $128(0.23)$ & $<0.001$ \\
\hline $\begin{array}{l}\text { Partial excision of mammary } \\
\text { gland }\end{array}$ & 63,033 & $1341(2.13)$ & $68(0.11)$ & $518(0.82)$ & $<0.001$ & $37(0.06)$ & $93(0.15)$ & $<0.001$ \\
\hline Appendectomy & 137,344 & $1291(0.94)$ & $88(0.06)$ & $936(0.68)$ & $<0.001$ & $58(0.04)$ & $205(0.15)$ & $<0.001$ \\
\hline Thyroidectomy & 51,506 & $1372(2.66)$ & $40(0.08)$ & $311(0.60)$ & $<0.001$ & $22(0.04)$ & $58(0.11)$ & $<0.001$ \\
\hline Sinus surgery & 158,677 & $275(0.17)$ & $39(0.02)$ & $828(0.52)$ & $<0.001$ & $17(0.01)$ & $98(0.06)$ & $<0.001$ \\
\hline Endoscopic sinus surgery & 109,454 & $801(0.73)$ & $32(0.03)$ & $546(0.50)$ & $<0.001$ & $14(0.01)$ & $68(0.06)$ & $<0.001$ \\
\hline Operation for hemorrhoid & 303,456 & $179(0.06)$ & $34(0.01)$ & $1367(0.45)$ & $<0.001$ & $18(0.01)$ & $140(0.05)$ & $<0.001$ \\
\hline Cesarean section & 255,600 & $690(0.27)$ & $16(0.01)$ & $668(0.26)$ & $<0.001$ & $10(0.003)$ & $74(0.03)$ & $<0.001$ \\
\hline Cleft lip and/or palate surgery & 1282 & $5(0.39)$ & - & $2(0.16)$ & - & $0(0.00)$ & $1(0.08)$ & - \\
\hline Tonsillectomy & 66,307 & $140(0.21)$ & $7(0.01)$ & $89(0.13)$ & $<0.001$ & $4(0.01)$ & $5(0.01)$ & 0.739 \\
\hline Total & $2,799,293$ & $158,987(5.68)$ & $6166(0.22)$ & $4517(1.95)$ & $<0.001$ & $2993(0.11)$ & $18,070(0.65)$ & $<0.001$ \\
\hline
\end{tabular}


Table 3. Type of TE within 6 months from the date of each surgery.

\begin{tabular}{|c|c|c|c|c|c|c|}
\hline \multirow{2}{*}{ Type of TE } & \multirow{2}{*}{ No. } & \multirow{2}{*}{ Details } & \multicolumn{2}{|c|}{$\begin{array}{l}\text { Total Claimed TE } \\
\quad(n=60,683)\end{array}$} & \multicolumn{2}{|c|}{$\begin{array}{l}\text { TE with Anticoagulant } \\
\text { Treatment }(n=21,603)\end{array}$} \\
\hline & & & $\begin{array}{l}\text { Number of } \\
\text { Patients, } n\end{array}$ & Events $(\%)$ & $\begin{array}{l}\text { Number of } \\
\text { Patients, } n\end{array}$ & Events $(\%)$ \\
\hline & 1 & I26 Pulmonary embolism & 2 & $0.003 \%$ & 2 & $0.009 \%$ \\
\hline & 2 & I80 Phlebitis and thrombophlebitis & 5 & $0.008 \%$ & - & $0.000 \%$ \\
\hline & 3 & $\begin{array}{l}\text { I80.0 Phlebitis and thrombophlebitis of } \\
\text { superficial vessels of lower extremities }\end{array}$ & 884 & $1.457 \%$ & 147 & $0.698 \%$ \\
\hline & 4 & $\begin{array}{l}\text { I } 80.1 \text { Phlebitis and thrombophlebitis of } \\
\text { femoral vein }\end{array}$ & 87 & $0.143 \%$ & 31 & $0.147 \%$ \\
\hline & 5 & $\begin{array}{l}\text { I80.2 Phlebitis and thrombophlebitis of } \\
\text { other deep vessels of lower extremities }\end{array}$ & 13,931 & $22.957 \%$ & 7717 & $36.638 \%$ \\
\hline & 6 & $\begin{array}{l}\text { I80.3 Phlebitis and thrombophlebitis of } \\
\text { lower extremities, unspecified }\end{array}$ & 3788 & $6.242 \%$ & 1299 & $6.167 \%$ \\
\hline & 7 & $\begin{array}{l}\text { I80.8 Phlebitis and thrombophlebitis of } \\
\text { other sites }\end{array}$ & 2811 & $4.632 \%$ & 350 & $1.662 \%$ \\
\hline & 8 & $\begin{array}{l}\text { I80.9 Phlebitis and thrombophlebitis of } \\
\text { unspecified site }\end{array}$ & 6977 & $11.497 \%$ & 1505 & $7.145 \%$ \\
\hline & 9 & I81 Portal vein thrombosis & 389 & $0.641 \%$ & 174 & $0.826 \%$ \\
\hline & 10 & $\begin{array}{l}\text { I82 Other venous embolism and } \\
\text { thrombosis }\end{array}$ & 8 & $0.013 \%$ & 1 & $0.005 \%$ \\
\hline & 11 & I82.0 Budd-Chiari syndrome & 55 & $0.091 \%$ & 12 & $0.057 \%$ \\
\hline & 12 & I82.1 Thrombophlebitis migrans & 11 & $0.018 \%$ & 2 & $0.009 \%$ \\
\hline & 13 & $\begin{array}{l}\text { I82.2 Embolism and thrombosis of vena } \\
\text { cava }\end{array}$ & 63 & $0.104 \%$ & 38 & $0.180 \%$ \\
\hline & 14 & $\begin{array}{l}\text { I } 82.3 \text { Embolism and thrombosis of renal } \\
\text { vein }\end{array}$ & 84 & $0.138 \%$ & 22 & $0.104 \%$ \\
\hline \multirow[t]{14}{*}{ Venous TE } & 15 & $\begin{array}{l}\text { I82.8 Embolism and thrombosis of other } \\
\text { specified veins }\end{array}$ & 2867 & $4.725 \%$ & 1538 & $7.302 \%$ \\
\hline & 16 & $\begin{array}{l}\text { I82.9 Embolism and thrombosis of } \\
\text { unspecified vein }\end{array}$ & 15,327 & $25.257 \%$ & 6067 & $28.804 \%$ \\
\hline & 17 & $\begin{array}{l}\text { I63.6 Cerebral infarction due to cerebral } \\
\text { venous thrombosis, nonpyogenic }\end{array}$ & 66 & $0.109 \%$ & 16 & $0.076 \%$ \\
\hline & 18 & $\begin{array}{l}\text { I67.6 Nonpyogenic thrombosis of } \\
\text { intracranial venous system }\end{array}$ & 50 & $0.082 \%$ & 12 & $0.057 \%$ \\
\hline & 19 & $\begin{array}{l}\text { O22.2 Superficial thrombophlebitis in } \\
\text { pregnancy }\end{array}$ & 3 & $0.005 \%$ & - & $0.000 \%$ \\
\hline & 20 & $\begin{array}{l}\text { O22.3 Deep phlebothrombosis in } \\
\text { pregnancy }\end{array}$ & 106 & $0.175 \%$ & 2 & $0.009 \%$ \\
\hline & 21 & $\begin{array}{l}\text { O22.5 Cerebral venous thrombosis in } \\
\text { pregnancy }\end{array}$ & 3 & $0.005 \%$ & - & $0.000 \%$ \\
\hline & 22 & $\begin{array}{l}\text { O87.1 Deep phlebothrombosis in the } \\
\text { puerperium }\end{array}$ & 126 & $0.208 \%$ & 11 & $0.052 \%$ \\
\hline & 23 & $\begin{array}{l}\text { O87.3 Cerebral venous thrombosis in } \\
\text { the peurperium }\end{array}$ & 3 & $0.005 \%$ & 2 & $0.009 \%$ \\
\hline & 24 & $\begin{array}{l}\text { G08 Intracranial and intraspinal } \\
\text { phlebitis and thrombophlebitis }\end{array}$ & 69 & $0.114 \%$ & 20 & $0.095 \%$ \\
\hline & 25 & G95 Other diseases of spinal cord & 0 & $0.000 \%$ & 0 & $0.000 \%$ \\
\hline & 26 & $\begin{array}{l}\text { K55.0 Acute vascular disorders of } \\
\text { intestine }\end{array}$ & 519 & $0.855 \%$ & 223 & $1.059 \%$ \\
\hline & 27 & $\begin{array}{l}\text { K55.1 Chronic vascular disorders of } \\
\text { intestine }\end{array}$ & 178 & $0.293 \%$ & 33 & $0.157 \%$ \\
\hline & & Total & 48,412 & $79.779 \%$ & 19,224 & $91.269 \%$ \\
\hline
\end{tabular}


Table 3. Cont.

\begin{tabular}{|c|c|c|c|c|c|c|}
\hline \multirow{2}{*}{ Type of TE } & \multirow{2}{*}{ No. } & \multirow{2}{*}{ Details } & \multicolumn{2}{|c|}{$\begin{array}{l}\text { Total Claimed TE } \\
\quad(n=60,683)\end{array}$} & \multicolumn{2}{|c|}{$\begin{array}{l}\text { TE with Anticoagulant } \\
\text { Treatment }(n=21,603)\end{array}$} \\
\hline & & & $\begin{array}{l}\text { Number of } \\
\text { Patients, } n\end{array}$ & Events $(\%)$ & $\begin{array}{l}\text { Number of } \\
\text { Patients, } n\end{array}$ & Events $(\%)$ \\
\hline \multirow{12}{*}{ Arterial TE } & 28 & $\begin{array}{l}\text { I21, I22, I24 Myocardial infarction and } \\
\text { other acute ischemic heart disease }\end{array}$ & 14 & $0.023 \%$ & 2 & $0.009 \%$ \\
\hline & 29 & I63 Cerebral infarction & 54 & $0.089 \%$ & 1 & $0.005 \%$ \\
\hline & 30 & $\begin{array}{l}\text { I74.0 Embolism and thrombosis of } \\
\text { abdominal aorta }\end{array}$ & 145 & $0.239 \%$ & 44 & $0.209 \%$ \\
\hline & 31 & $\begin{array}{l}\text { I74.1 Embolism and thrombosis of other } \\
\text { and unspecified parts of aorta }\end{array}$ & 159 & $0.262 \%$ & 51 & $0.242 \%$ \\
\hline & 32 & $\begin{array}{l}\text { I74.2 Embolism and thrombosis of } \\
\text { arteries of upper extremities }\end{array}$ & 163 & $0.269 \%$ & 61 & $0.290 \%$ \\
\hline & 33 & $\begin{array}{l}\text { I74.3 Embolism and thrombosis of } \\
\text { arteries of lower extremities }\end{array}$ & 3 & $0.005 \%$ & - & $0.000 \%$ \\
\hline & 34 & $\begin{array}{l}\text { I74.4 Embolism and thrombosis of } \\
\text { arteries of extremities, unspecified }\end{array}$ & 1614 & $2.660 \%$ & 402 & $1.909 \%$ \\
\hline & 35 & $\begin{array}{l}\text { I74.5 Embolism and thrombosis of iliac } \\
\text { artery }\end{array}$ & 203 & $0.335 \%$ & 74 & $0.351 \%$ \\
\hline & 36 & $\begin{array}{l}\text { I74.8 Embolism and thrombosis of other } \\
\text { arteries }\end{array}$ & 2757 & $4.543 \%$ & 484 & $2.298 \%$ \\
\hline & 37 & $\begin{array}{l}\text { I74.9 Embolism and thrombosis of } \\
\text { unspecified artery }\end{array}$ & 6686 & $11.018 \%$ & 478 & $2.269 \%$ \\
\hline & 38 & N28.0 Ischemia and infarction of kidney & 473 & $0.779 \%$ & 242 & $1.149 \%$ \\
\hline & & Total & 12,271 & $20.221 \%$ & 1839 & $8.731 \%$ \\
\hline
\end{tabular}

Abbreviation: TE, thromboembolism.

\subsection{Relative risk of TE According to Surgery Type}

To analyze the relative risk of TE for each surgery, the adjusted ORs for TE events were calculated, after correcting for TE risk factors. In this study, $2.84 \%$ of patients $(79,498 /$ 2,799,293 patients) had a history of cancer, $0.002 \%(48 / 2,799,293$ patients) had atrial fibrillation or atrial flutter, $0.44 \%(12,420 / 2,799,293$ patients) had a history of TE, $11.11 \%$ $(310,994 / 2,799,293$ patients) were taking antiplatelet or anticoagulant drugs between 2 weeks and 3 months prior to surgery, $7.03 \%$ (196,745/2,799,293 patients) were taking antiplatelet or anticoagulant drugs on the day of surgery, and 5.68\% (158,987/2,799,293 patients) underwent prophylactic anticoagulant treatment. The baseline characteristics (whole cohort and each surgery group) and the ORs and $95 \% \mathrm{CI}$ of each risk factor are presented in Tables S4 and S5. Transurethral prostatectomy was used as a reference surgery.

The relative risk of the total claimed venous TE for each surgery, after correcting for TE risk factors, revealed that the highest risk was associated with hip replacement (OR $=7.771,95 \%$ CI: 6.749-8.946), total knee replacement (OR = 7.755, 95\% CI: 6.747-8.913), and coronary artery bypass graft surgery $(\mathrm{OR}=5.183,95 \% \mathrm{CI}: 4.234-6.344)$, followed by spine surgery ( $\mathrm{OR}=4.941,95 \% \mathrm{CI}$ : $4.308-5.667)$, cardiac surgery (except for coronary artery bypass graft surgery) $(\mathrm{OR}=4.584,95 \% \mathrm{CI}: 3.769-5.575)$, partial hepatectomy (OR $=4.032,95 \%$ CI: 3.384-4.804), gastrectomy (OR $=3.911,95 \% \mathrm{CI}: 3.363-4.549)$, and hysterectomy $(\mathrm{OR}=3.751,95 \% \mathrm{CI}$ : 3.196-4.403) (Figure 2A). The relative risk of the total claimed arterial TE for each surgery after correcting for TE risk factors revealed that the highest risk was associated with cardiac surgery (except for coronary artery bypass graft surgery) $(\mathrm{OR}=12.969,95 \% \mathrm{CI}$ : 9.422-17.851), total knee replacement $(\mathrm{OR}=11.061,95 \% \mathrm{CI}: 8.669-14.111)$, and coronary artery bypass graft surgery $(\mathrm{OR}=10.567$, 95\% CI: 7.610-14.673) (Figure 2B). 
(A) Venous thromboembolism

\begin{tabular}{|c|c|c|c|}
\hline Surgery & Odds ratio & $\begin{array}{c}\text { 95\% confidential } \\
\text { interval }\end{array}$ \\
\hline Hip replacement & 7.771 & 6.749 & 8.946 \\
\hline Total knee replacement & 7.755 & 6.747 & 8.913 \\
\hline CABG & 5.183 & 4.234 & 6.344 \\
\hline Spine surgery & 4.941 & 4.308 & 5.667 \\
\hline Cardiac surgery (except CABG) & 4.584 & 3.769 & 5.575 \\
\hline Partial hepatectomy & 4.032 & 3.384 & 4.804 \\
\hline Gastrectomy & 3.911 & 3.363 & 4.549 \\
\hline Hysterectomy & 3.751 & 3.196 & 4.403 \\
\hline Endoscopic spine surgery & 3.530 & 2.963 & 4.206 \\
\hline Brain tumor surgery & 3.093 & 2.565 & 3.728 \\
\hline Skull base surgery & 1.985 & 1.008 & 3.909 \\
\hline Cholecystectomy & 1.442 & 1.249 & 1.665 \\
\hline Open prostatectomy & 1.432 & 1.044 & 1.965 \\
\hline Total mastectomy & 1.410 & 1.167 & 1.703 \\
\hline Partial excision of mammary gland & 1.002 & 0.849 & 1.181 \\
\hline Transurethral prostatectomy & 1 & - & - \\
\hline Repair of inguinal hernia & 0.910 & 0.773 & 1.072 \\
\hline Appendectomy & 0.791 & 0.678 & 0.923 \\
\hline Cataract surgery & 0.684 & 0.596 & 0.785 \\
\hline Thyroidectomy & 0.531 & 0.439 & 0.642 \\
\hline Endoscopic sinus surgery & 0.506 & 0.428 & 0.598 \\
\hline Operation for hemorrhoid & 0.420 & 0.362 & 0.489 \\
\hline Caesarean section & 0.395 & 0.337 & 0.464 \\
\hline Sinus surgery & 0.381 & 0.324 & 0.449 \\
\hline Tonsillectomy & 0.216 & 0.167 & 0.279 \\
\hline Cleft lip and/or palate surgery & $<0.001$ & $<0.001$ & $>999.999$ \\
\hline & & &
\end{tabular}

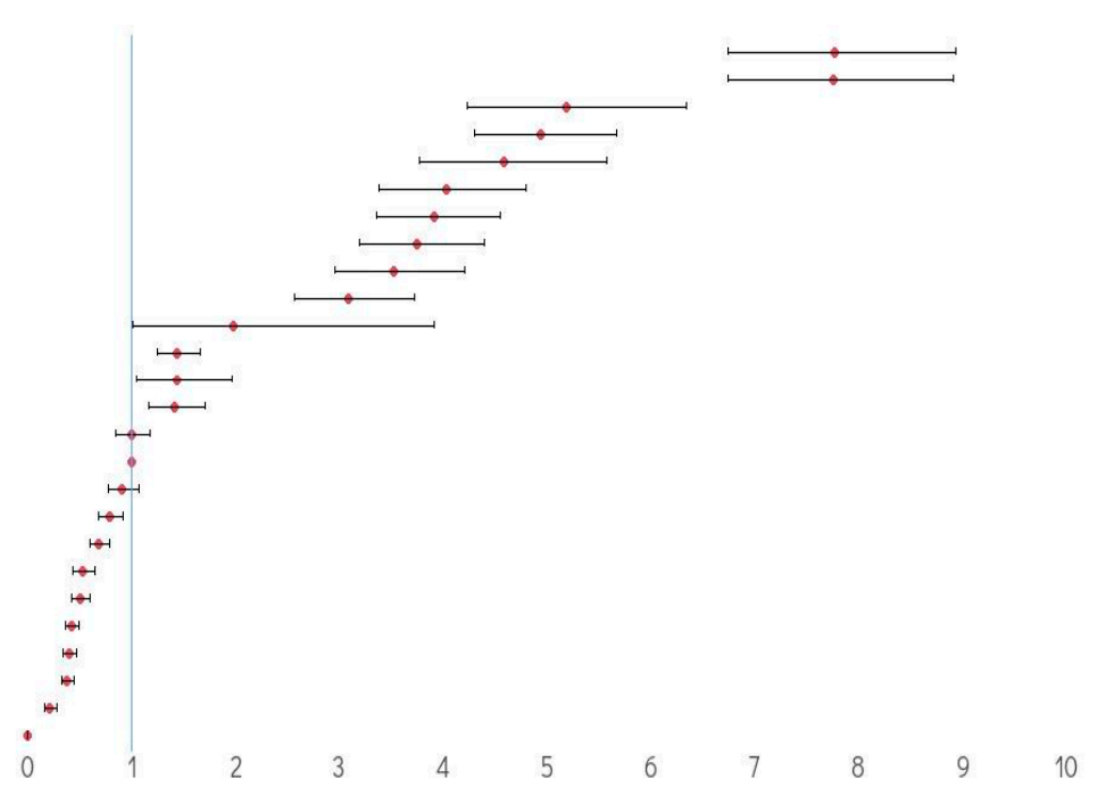

(B) Arterial thrombocmbolism

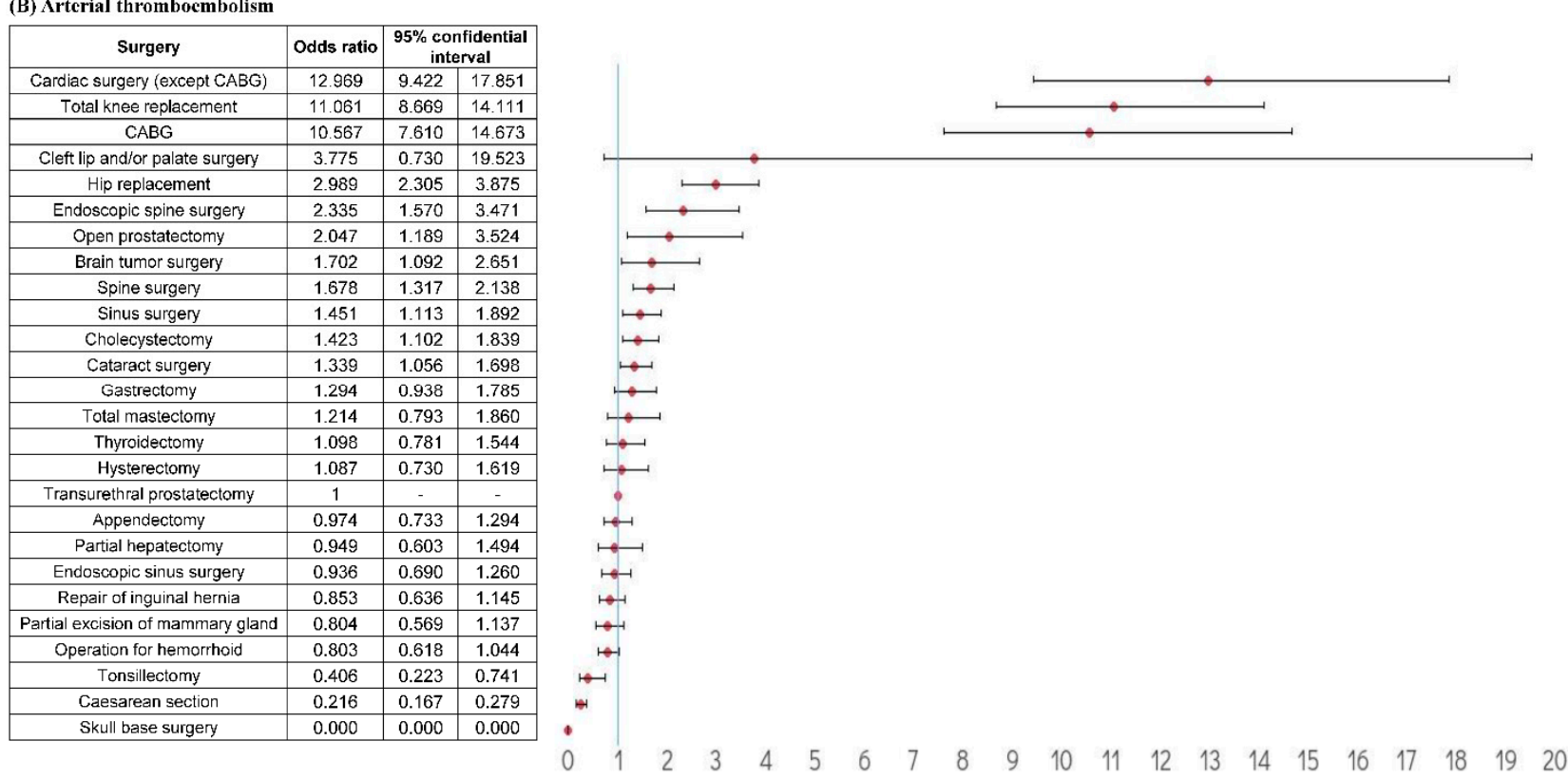

Figure 2. Odds ratios of total claimed thromboembolism events for each type of surgery after correcting for thromboembolism risk factors. Abbreviation: CABG, coronary artery bypass graft. (A) The total claimed venous thromboembolism events, (B) the total claimed arterial thromboembolism events.

The relative risk of venous TE with anticoagulant treatment for each surgery after correcting for TE risk factors revealed that the highest risk was associated with hysterectomy $(\mathrm{OR}=9.355$; 95\% CI: 7.145-12.247), partial hepatectomy (OR = 6.015; 95\% CI: 4.547-7.958), and hip replacement $(\mathrm{OR}=5.915,95 \% \mathrm{CI}: 4.598-7.610)$, followed by cardiac surgery (except for coronary artery bypass graft surgery) $(\mathrm{OR}=5.812,95 \% \mathrm{CI}: 4.348-7.768)$, total knee replacement ( $\mathrm{OR}=5.469,95 \% \mathrm{CI}: 4.257-7.026)$, coronary artery bypass graft surgery $(\mathrm{OR}=5.214,95 \%$ CI: $3.865-7.033)$, and brain tumor surgery (OR $=4.693,95 \%$ CI: $3.482-6.325)$ (Figure 3A). The relative risk of arterial TE with anticoagulant treatment for each surgery after correcting for the TE risk factors revealed that the highest risk was associated with cardiac surgery (except for coronary artery bypass graft surgery) (OR = 14.958, 95\% CI: 7.826-28.590), 
cleft lip and/or palate surgery (OR $=13.000,95 \%$ CI: 1.630-103.672), and coronary artery bypass graft surgery ( $\mathrm{OR}=7.511,95 \% \mathrm{CI}$ : 3.863-14.607) (Figure 3B).

(A) Venous thromboembolism

\begin{tabular}{|c|c|c|c|}
\hline Surgery & Odds ratio & \multicolumn{2}{|c|}{$\begin{array}{c}\text { confidential } \\
\text { interval }\end{array}$} \\
\hline Hysterectomy & 9.355 & 7.145 & 12.247 \\
\hline Partial hepatectomy & 6.015 & 4.547 & 7.958 \\
\hline Hip replacement & 5.915 & 4.598 & 7.610 \\
\hline Cardiac surgery (except CABG) & 5.812 & 4.348 & 7.768 \\
\hline Total knee replacement & 5.469 & 4.257 & 7.026 \\
\hline CABG & 5.214 & 3.865 & 7.033 \\
\hline Brain tumor surgery & 4.693 & 3.482 & 6.325 \\
\hline Gastrectomy & 2.080 & 1.573 & 2.750 \\
\hline Total mastectomy & 2.057 & 1.482 & 2.856 \\
\hline Spine surgery & 2.050 & 1.596 & 2.633 \\
\hline Skull base surgery & 1.997 & 0.643 & 6.207 \\
\hline Cholecystectomy & 1.383 & 1.067 & 1.794 \\
\hline Appendectomy & 1.241 & 0.935 & 1.646 \\
\hline Repair of inguinal hernia & 1.223 & 0.900 & 1.662 \\
\hline Partial excision of mammary gland & 1.163 & 0.850 & 1.592 \\
\hline Open prostatectomy & 1.223 & 0.900 & 1.662 \\
\hline Cataract surgery & 1.016 & 0.790 & 1.306 \\
\hline Transurethral prostatectomy & 1 & - & - \\
\hline Endoscopic spine surgery & 0.904 & 0.550 & 1.485 \\
\hline Thyroidectomy & 0.593 & 0.415 & 0.846 \\
\hline Endoscopic sinus surgery & 0.418 & 0.295 & 0.593 \\
\hline Sinus surgery & 0.385 & 0.278 & 0.534 \\
\hline Operation for hemorrhoid & 0.361 & 0.267 & 0.487 \\
\hline Caesarean section & 0.333 & 0.237 & 0.467 \\
\hline Tonsillectomy & 0.144 & 0.069 & 0.302 \\
\hline Cleft lip and/or palate surgery & $<0.001$ & $<0.001$ & $>999.999$ \\
\hline & & &
\end{tabular}

4

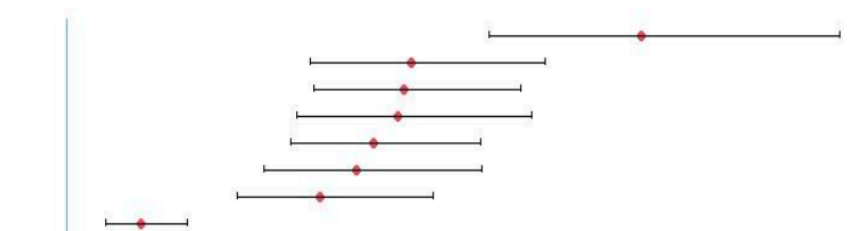

(B) Arterial thromboembolism

\begin{tabular}{|c|c|c|c|}
\hline \multirow{2}{*}{$\begin{array}{c}\text { Surgery } \\
\text { Cardiac surgery (except CABG) } \\
\end{array}$} & \multirow{2}{*}{\begin{tabular}{|c|} 
Odds ratio \\
14.958 \\
\end{tabular}} & \multicolumn{2}{|c|}{\begin{tabular}{|c|}
$95 \%$ confidential \\
interval
\end{tabular}} \\
\hline & & 7.826 & 28.590 \\
\hline Cleft lip and/or palate surgery & 13.000 & 1.630 & 103.672 \\
\hline CABG & 7.511 & 3.863 & 14.607 \\
\hline Hip replacement & 3.153 & 1.684 & 5.902 \\
\hline Total knee replacement & 2.772 & 1.489 & 5.159 \\
\hline Cholecystectomy & 2.035 & 1.082 & 3.825 \\
\hline Hysterectomy & 1.931 & 0.851 & 4.383 \\
\hline Repair of inguinal hernia & 1.818 & 0.897 & 3.685 \\
\hline Partial hepatectomy & 1.790 & 0.802 & 3.993 \\
\hline Spine surgery & 1.744 & 0.958 & 3.287 \\
\hline Gastrectomy & 1.682 & 0.828 & 3.415 \\
\hline Cataract surgery & 1.627 & 0.883 & 2.999 \\
\hline Brain tumor surgery & 1.607 & 0.633 & 4.085 \\
\hline Appendectomy & 1.417 & 0.698 & 2.877 \\
\hline Partial excision of mammary gland & 1.260 & 0.544 & 2.918 \\
\hline Thyroidectomy & 1.186 & 0.497 & 2.832 \\
\hline Total mastectomy & 1.133 & 0.387 & 3.315 \\
\hline Transurethral prostatectomy & 1 & - & - \\
\hline Endoscopic sinus surgery & 0.914 & 0.417 & 2.001 \\
\hline Sinus surgery & 0.660 & 0.307 & 1.422 \\
\hline Operation for hemorrhoid & 0.453 & 0.214 & 0.961 \\
\hline Endoscopic spine surgery & 0.407 & 0.052 & 3.177 \\
\hline Open prostatectomy & 0.344 & 0.043 & 2.747 \\
\hline Caesarean section & 0.274 & 0.093 & 0.808 \\
\hline Tonsillectomy & 0.203 & 0.026 & 1.589 \\
\hline Skull base surgery & $<0.001$ & $<0.001$ & $>999.999$ \\
\hline
\end{tabular}

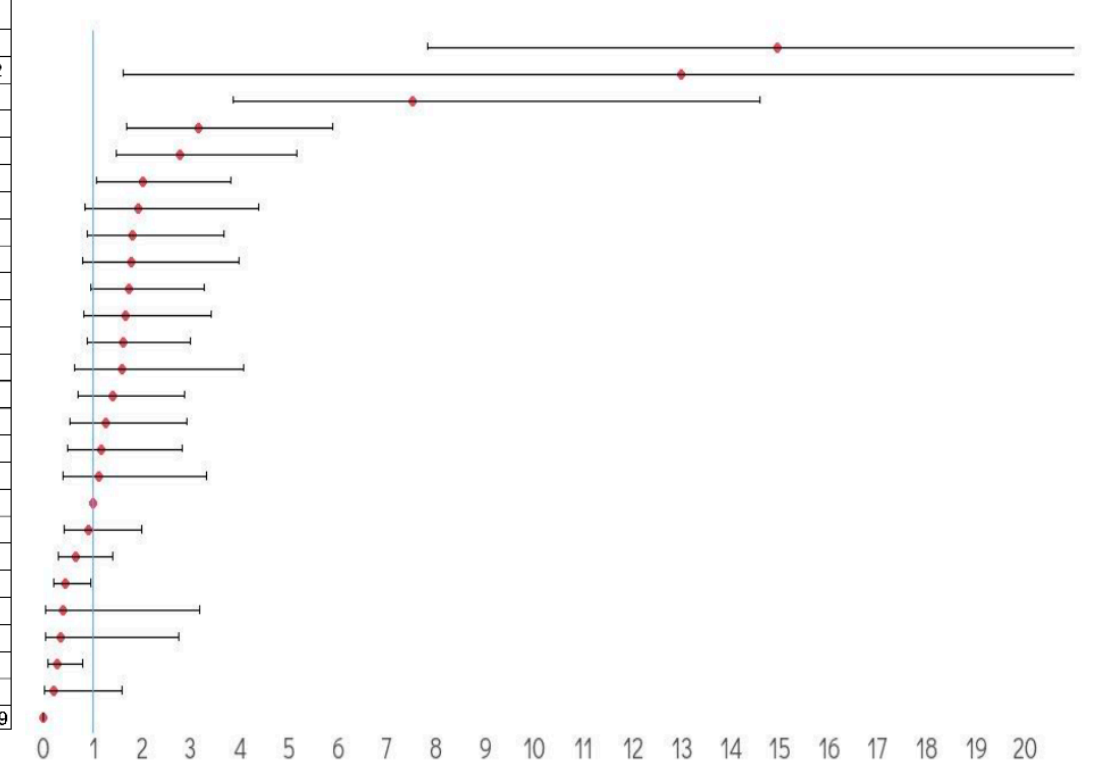

Figure 3. Odds ratios of thromboembolism events with anticoagulant treatment for each type of surgery after correcting for thromboembolism risk factors. Abbreviation: CABG, coronary artery bypass graft. (A) venous thromboembolism events with anticoagulant treatment (B) arterial thromboembolism events with anticoagulant treatment.

\section{Discussion}

In this study of 2,799,293 patients who underwent selected surgeries from 1 December 2017 to 31 August 2019 in the Republic of Korea, 60,683 patients had claimed TE events (average: $2.17 \%$, and range according to surgery type: $0.14-12.77 \%$ ) and $21,063 \mathrm{had}$ a TE event with anticoagulant treatment (average: $0.75 \%$, and range according to surgery type: $0.01-7.40 \%$ ). Approximately $65 \%$ of TE events occurred within 1 month of surgery, and the incidence of TE events differed according to the surgery type. Patients undergoing total knee replacement and hip replacement, i.e., $12.77 \%$ (13,811 of 108,111 patients) and 
$11.46 \%$ (4975 of 43,415 patients), respectively, had a higher incidence of total claimed TE. In addition, the relative risk of venous TE in these surgeries was also higher than that in other procedures. Several surgeries, including hysterectomy, partial hepatectomy, and gastrectomy, also showed a relatively higher risk of venous TE. The relative risk of arterial TE was the highest in cardiac surgery, total knee replacement, and hip replacement.

In Western countries, the incidence of postoperative TE events in patients undergoing total knee or hip replacement and spine surgery without TE prophylaxis ranges from $40 \%$ to $60 \%$ and $15 \%$ to $40 \%$, respectively [18-20]. In Asian populations, the incidence of TE events reportedly ranges from $10 \%$ to $60 \%$ in total knee or hip replacement surgeries and approximately $30 \%$ in spine surgery, which is relatively lower than the rates in the Western population [21-23]. When pharmacological prophylaxis is added, postoperative TE events can be reduced by approximately $70-90 \%$ or more [24-26]. In this study, the incidence of total claimed TE in total knee replacement, hip replacement, and spine surgery was $12.77 \%$, $11.46 \%$, and $5.98 \%$, respectively, which are higher incidence rates than those reported in previous studies [18-26]. Even considering the incidence of TE with anticoagulant treatment, total knee replacement and hip replacement were associated with a higher incidence of $7.4 \%$ and $7.2 \%$, respectively. There are several possible explanations for these differences. First, previous studies focused on reporting the incidence of deep vein thrombosis of the lower extremities or pulmonary embolism. However, this study reported all TE events in the real world, including venous TE and arterial TE, using claims data. Second, adherence to postoperative TE prophylaxis, especially pharmacological prophylaxis, is usually lower in clinical practice than the guideline recommendations according to patients' condition or the guidelines of each institution [27-29]. In fact, in this study, the rates of pharmacological prophylaxis were $52.62 \%$ and $41.17 \%$ in total knee replacement and hip replacement surgery, respectively, which are generally recommended for pharmacological prophylaxis. In addition, in the patient group that underwent pharmacological prophylaxis, it was confirmed that the incidence of postoperative TE events was reduced by approximately $90 \%$ compared with that in the no treatment group, as demonstrated in previous studies [24-26]. Taken together, in the real world, the incidence of postoperative TE may appear higher than that expected in previous studies because of low compliance with pharmacological prophylaxis.

Among all claimed TE events, TE events with anticoagulant treatment warranty the attention of physicians, excluding cases of superficial TE or subclinical TE events (Table 1). However, in the case of patients undergoing cardiac surgery, in which postoperative anticoagulant treatment is used in most patients, TE events with anticoagulant treatment may be overestimated. Conversely, in spine surgery, where the use of anticoagulant treatment is often difficult, because of the risk of bleeding, TE events with anticoagulant treatment in these patients may be underestimated. Therefore, this study presented both the total claimed TE, and TE with anticoagulant treatment, as the primary endpoints. However, the duration of anticoagulant treatment was shorter than that in the recommended guidelines for patients with postoperative TE events (median, 13 days; range, $1-442$ days) [30,31]. This may be because of poor compliance with postoperative TE treatment guidelines, or patients using anticoagulant drugs for reasons other than postoperative TE treatment may have been included in the analysis. Thus, proper interpretation is necessary, to consider this aspect when applying the results of this study to clinical practice.

This study had the following differences compared to previous studies. First, as mentioned above, in most studies, TE events were counted by focusing on pulmonary embolism and deep vein thrombosis of the lower extremities [32,33]. Although pulmonary embolism and deep vein thrombosis of the extremities are clinically meaningful, in the real world, TE may occur in rare locations, such as intra-abdominally; and arterial TE, such as myocardial infarction and stroke, may also occur. In this study, we presented the situation of all TE events that can occur in the real world. Second, existing studies reported the risk of TE limited to one-area surgery or cancer-related surgeries [32-35]. Based on this information, it is impossible to sufficiently explain the relative risk for TE in each type of surgery in patients undergoing that surgery. Unlike other studies, this study aimed to 
present the relative risk for TE according to the type of surgery in patients who underwent commonly performed surgeries in clinical practice. Third, this study also presented the incidence of arterial TE in the real world. Although the rate was lower than that of venous $\mathrm{TE}$, fatal arterial TE, such as that resulting in postoperative myocardial infarction or stroke, can occur [36-39]. However, there are insufficient data on the incidence of arterial TE in surgical patients in the real world, and this study manifested this fact.

This study had several limitations. First, since the analysis used claims data, there were limitations in identifying all TE risk factors, such as information on individual and family medical history related to thrombophilia and detailed laboratory tests. Furthermore, it was not possible to correct for cases of mechanical heart valve surgery as a major TE risk factor, because we analyzed patients who underwent each selected surgery for the first time during the study period. However, the proportion of patients who had undergone mechanical heart valve surgery among all the patients was $0.002 \%$ (5921/2,799,293 patients); therefore, the effect of this was small. Second, because details such as the patient's condition at the time of each surgery, purpose of the surgery, and situation at the time of the surgery were unknown, other factors in each surgery that were associated with an increased relative risk of TE could not be analyzed. Nevertheless, this study is considered to be meaningful because it presents the incidence and pattern of all postoperative venous or arterial TE of the commonly practiced surgeries in the real world and relative risk according to the type of surgery, using a nationally representative database.

In conclusion, in the real world, the incidence of postoperative venous TE in total knee replacement and hip replacement is still high, and some surgeries could have a relatively higher risk of venous TE than other surgeries. For patients undergoing these surgeries, studies to reduce the incidence of postoperative TE in clinical practice should be conducted.

Supplementary Materials: The following supporting information can be downloaded at: https: / / www.mdpi.com/article/10.3390/jcm11061477/s1, Table S1: Classification codes for type of each surgery; Table S2: Type of total claimed thromboembolism for each surgery; Table S3: Type of thromboembolism with anticoagulation treatment for each surgery; Table S4: Baseline characteristics of the whole cohort and those of each surgery group; Table S5: Multivariate analysis of variables associated with postoperative thromboembolism events.

Author Contributions: B.S.K. and K.-W.K. designed the study. K.-W.K. and J.Y.L. analyzed the data and summarized the results. K.-W.K. wrote the manuscript. B.-H.L., M.J.J., E.S.Y., D.S.K., S.R.L., H.J.S., C.W.C., Y.P. and B.S.K. reviewed the data analysis. All authors have read and agreed to the published version of the manuscript.

Funding: This research was supported by a grant from Korea University (grant number: K2125711).

Institutional Review Board Statement: All procedures involving human participants were performed in accordance with the ethical standards of the institutional and national research committees and in accordance with the 1964 Helsinki Declaration and its later amendments or comparable ethical standards. The study was approved by the institutional review board of the Korea University Anam Hospital (No. 2020AN0136)

Informed Consent Statement: The requirement for informed consent was waived by the institutional review board of the Korea University Anam Hospital (No. 2020AN0136), owing to the use of anonymized patient data.

Data Availability Statement: Data are available from the corresponding author upon reasonable request.

Conflicts of Interest: The authors declare that they have no competing interest.

\section{References}

1. Jerjes-Sanchez, C. Venous and arterial thrombosis: A continuous spectrum of the same disease? Eur. Heart J. 2004, 26, 3-4. [CrossRef] [PubMed]

2. Kreutzer, L.; Minami, C.; Yang, A. Preventing venous thromboembolism after surgery. JAMA 2016, 315, 2136. [CrossRef] [PubMed]

3. D'Astous, J.; Liederman, Z.; Douketis, J.D. Venous thromboembolism prophylaxis in high-risk orthopedic and cancer surgery. Postgrad. Med. 2021, 133, 20-26. [CrossRef] [PubMed] 
4. Spyropoulos, A.C.; Douketis, J.D. How I treat anticoagulated patients undergoing an elective procedure or surgery. Blood 2012, 120, 2954-2962. [CrossRef] [PubMed]

5. Anderson, D.R.; Morgano, G.P.; Bennett, C.; Dentali, F.; Francis, C.W.; Garcia, D.A.; Kahn, S.R.; Rahman, M.; Rajasekhar, A.; Rogers, F.B.; et al. American Society of Hematology 2019 guidelines for management of venous thromboembolism: Prevention of venous thromboembolism in surgical hospitalized patients. Blood Adv. 2019, 3, 3898-3944. [CrossRef]

6. Kyrle, P.A.; Eichinger, S. Deep vein thrombosis. Lancet 2005, 365, 1163-1174. [CrossRef]

7. van Veen, J.J.; Makris, M. Management of peri-operative anti-thrombotic therapy. Anaesthesia 2015, 70, 58-e23. [CrossRef]

8. Falck-Ytter, Y.; Francis, C.W.; Johanson, N.A.; Curley, C.; Dahl, O.E.; Schulman, S.; Ortel, T.L.; Pauker, S.G.; Colwell, C.W., Jr. Prevention of VTE in orthopedic surgery patients: Antithrombotic therapy and prevention of thrombosis, 9th ed: American College of Chest Physicians Evidence-Based Clinical Practice Guidelines. CHEST 2012, 141, e278S-e325S. [CrossRef]

9. Gee, E. The National VTE Exemplar Centres Network response to implementation of updated NICE guidance: Venous thromboembolism in over 16s: Reducing the risk of hospital-acquired deep vein thrombosis or pulmonary embolism (NG89). Br. J. Haematol. 2019, 186, 792-793. [CrossRef]

10. Cronin, M.; Dengler, N.; Krauss, E.S.; Segal, A.; Wei, N.; Daly, M.; Mota, F.; Caprini, J.A. Completion of the Updated Caprini Risk Assessment Model (2013 Version). Clin. Appl. Thromb. Hemost. 2019, 25, 1076029619838052. [CrossRef]

11. Rogers, S.O., Jr.; Kilaru, R.K.; Hosokawa, P.; Henderson, W.G.; Zinner, M.J.; Khuri, S.F. Multivariable predictors of postoperative venous thromboembolic events after general and vascular surgery: Results from the patient safety in surgery study. J. Am. Coll. Surg. 2007, 204, 1211-1221. [CrossRef]

12. Afshari, A.; Ageno, W.; Ahmed, A.; Duranteau, J.; Faraoni, D.; Kozek-Langenecker, S.; Llau, J.; Nizard, J.; Solca, M.; Stensballe, J.; et al. European guidelines on perioperative venous thromboembolism prophylaxis: Executive summary. Eur. J. Anaesthesiol. 2018, 35, 77-83. [CrossRef]

13. Gould, M.K.; Garcia, D.A.; Wren, S.M.; Karanicolas, P.J.; Arcelus, J.I.; Heit, J.A.; Samama, C.M. Prevention of VTE in nonorthopedic surgical patients: Antithrombotic therapy and prevention of thrombosis, 9th ed: American College of Chest Physicians EvidenceBased Clinical Practice Guidelines. CHEST 2012, 141, e227S-e277S. [CrossRef]

14. Caprini, J.A. Thrombosis risk assessment as a guide to quality patient care. Dis. Mon. 2005, 51, 70-78. [CrossRef]

15. Bahl, V.; Hu, H.M.; Henke, P.K.; Wakefield, T.W.; Campbell, D.A., Jr.; Caprini, J.A. A validation study of a retrospective venous thromboembolism risk scoring method. Ann. Surg. 2010, 251, 344-350. [CrossRef]

16. Cheol Seong, S.; Kim, Y.Y.; Khang, Y.H.; Heon Park, J.; Kang, H.J.; Lee, H.; Do, C.H.; Song, J.S.; Hyon Bang, J.; Ha, S.; et al. Data resource profile: The national health information database of the national health insurance service in South Korea. Int. J. Epidemiol. 2017, 46, 799-800. [CrossRef]

17. Kim, L.; Kim, J.A.; Kim, S. A guide for the utilization of health insurance review and assessment service national patient samples. Epidemiol. Health 2014, 36, e2014008. [CrossRef]

18. Geerts, W.H.; Bergqvist, D.; Pineo, G.F.; Heit, J.A.; Samama, C.M.; Lassen, M.R.; Colwell, C.W. Prevention of venous thromboembolism: American College of Chest Physicians Evidence-Based Clinical Practice Guidelines (8th Edition). CHEST 2008, 133, 381s-453s. [CrossRef]

19. Geerts, W.H.; Pineo, G.F.; Heit, J.A.; Bergqvist, D.; Lassen, M.R.; Colwell, C.W.; Ray, J.G. Prevention of venous thromboembolism: The Seventh ACCP Conference on Antithrombotic and Thrombolytic Therapy. CHEST 2004, 126, 338s-400s. [CrossRef]

20. Kepler, C.K.; McKenzie, J.; Kreitz, T.; Vaccaro, A. Venous thromboembolism prophylaxis in spine surgery. J. Am. Acad. Orthop. Surg. 2018, 26, 489-500. [CrossRef]

21. Liew, N.C.; Gul, Y.; Moissinac, K. Postoperative venous thromboembolism in Asia: A critical appraisal of its incidence. Asian J. Surg. 2003, 26, 154-158. [CrossRef]

22. Do, J.G.; Kim, D.H.; Sung, D.H. Incidence of deep vein thrombosis after spinal cord injury in Korean patients at acute rehabilitation unit. J. Korean Med. Sci. 2013, 28, 1382-1387. [CrossRef] [PubMed]

23. Leizorovicz, A.; Turpie, A.G.; Cohen, A.T.; Wong, L.; Yoo, M.C.; Dans, A. Epidemiology of venous thromboembolism in Asian patients undergoing major orthopedic surgery without thromboprophylaxis. The SMART study. J. Thromb. Haemost. 2005, 3, 28-34. [CrossRef] [PubMed]

24. Cox, J.B.; Weaver, K.J.; Neal, D.W.; Jacob, R.P.; Hoh, D.J. Decreased incidence of venous thromboembolism after spine surgery with early multimodal prophylaxis: Clinical article. J. Neurosurg. Spine 2014, 21, 677-684. [CrossRef]

25. Jung, Y.J.; Seo, H.S.; Park, C.H.; Jeon, H.M.; Kim, J.I.; Yim, H.W.; Song, K.Y. Venous thromboembolism incidence and prophylaxis use after gastrectomy among Korean patients with gastric adenocarcinoma: The PROTECTOR randomized clinical trial. JAMA Surg. 2018, 153, 939-946. [CrossRef]

26. Emoto, S.; Nozawa, H.; Kawai, K.; Hata, K.; Tanaka, T.; Shuno, Y.; Nishikawa, T.; Sasaki, K.; Kaneko, M.; Hiyoshi, M.; et al. Venous thromboembolism in colorectal surgery: Incidence, risk factors, and prophylaxis. Asian J. Surg. 2019, 42, 863-873. [CrossRef]

27. Manoucheri, R.; Fallahi, M.J. Adherence to venous thromboprophylaxis guidelines for medical and surgical inpatients of teaching hospitals, Shiraz-Iran. Tanaffos 2015, 14, 17-26.

28. Geahchan, N.; Basile, M.; Tohmeh, M.; on behalf of the DIONYS registry. Venous thromboembolism prophylaxis in patients undergoing abdominal and pelvic cancer surgery: Adherence and compliance to ACCP guidelines in DIONYS registry. SpringerPlus 2016, 5, 1541. [CrossRef] 
29. Galante, M.; Languasco, A.; Gotta, D.; Bell, S.; Lancelotti, T.; Knaze, V.; Saubidet, C.L.; Grand, B.; Milberg, M. Venous thromboprophylaxis in general surgery ward admissions: Strategies for improvement. Int. J. Qual. Health Care 2012, 24, $649-656$. [CrossRef]

30. Kearon, C.; Akl, E.A.; Ornelas, J.; Blaivas, A.; Jimenez, D.; Bounameaux, H.; Huisman, M.; King, C.S.; Morris, T.A.; Sood, N.; et al. Antithrombotic therapy for VTE disease: CHEST guideline and expert panel report. CHEST 2016, 149, 315-352. [CrossRef]

31. Ortel, T.L.; Neumann, I.; Ageno, W.; Beyth, R.; Clark, N.P.; Cuker, A.; Hutten, B.A.; Jaff, M.R.; Manja, V.; Schulman, S.; et al. American Society of Hematology 2020 guidelines for management of venous thromboembolism: Treatment of deep vein thrombosis and pulmonary embolism. Blood Adv. 2020, 4, 4693-4738. [CrossRef]

32. Kanchanabat, B.; Stapanavatr, W.; Meknavin, S.; Soorapanth, C.; Sumanasrethakul, C.; Kanchanasuttirak, P. Systematic review and meta-analysis on the rate of postoperative venous thromboembolism in orthopaedic surgery in Asian patients without thromboprophylaxis. Br. J. Surg. 2011, 98, 1356-1364. [CrossRef]

33. Yhim, H.Y.; Jang, M.J.; Bang, S.M.; Kim, K.H.; Kim, Y.K.; Nam, S.H.; Bae, S.H.; Kim, S.H.; Mun, Y.C.; Kim, I.; et al. Incidence of venous thromboembolism following major surgery in Korea: From the Health Insurance Review and Assessment Service database. J. Thromb. Haemost. 2014, 12, 1035-1043. [CrossRef]

34. Lewis-Lloyd, C.A.; Pettitt, E.M.; Adiamah, A.; Crooks, C.J.; Humes, D.J. Risk of postoperative venous thromboembolism after surgery for colorectal malignancy: A systematic review and meta-analysis. Dis. Colon Rectum 2021, 64, 484-496. [CrossRef]

35. Moubayed, S.P.; Eskander, A.; Mourad, M.W.; Most, S.P. Systematic review and meta-analysis of venous thromboembolism in otolaryngology-head and neck surgery. Head Neck 2017, 39, 1249-1258. [CrossRef]

36. Dong, Y.; Cao, W.; Cheng, X.; Fang, K.; Zhang, X.; Gu, Y.; Leng, B.; Dong, Q. Risk factors and stroke characteristic in patients with postoperative strokes. J. Stroke Cerebrovasc. Dis. 2017, 26, 1635-1640. [CrossRef]

37. Blacker, D.J. In-hospital stroke. Lancet Neurol. 2003, 2, 741-746. [CrossRef]

38. Sellers, D.; Srinivas, C.; Djaiani, G. Cardiovascular complications after non-cardiac surgery. Anaesthesia 2018, 73 (Suppl. S1), $34-42$. [CrossRef]

39. Sahara, K.; Ishibe, A.; Yabuno, T.; Kondo, H.; Nakayama, G.; Yasuda, S.; Nishida, T.; Watanabe, J.; Uranaka, Y.; Akiyama, H.; et al. Acute iliac arterial thrombosis during laparoscopic abdominoperineal resection. J. Surg. Case Rep. 2019, 2019, rjz020. [CrossRef] 